\title{
International biotechnology collaborations: Points to consider
}

\author{
There is light at the end of the transatlantic tunnel.
}

\section{Wolfgang Stoiber}

Financial light is what most biotechnology companies are looking for in these dark days of rock-bottom markets, budget-constrained pharmaceutical companies, and fallen business angels. It is not easy to find. One way biotechnology executives are able to meet their growth needs in this environment is to burn the midnight oil seeking creative ways to structure deals. For both the US and Europe, the exciting news is that creating an international collaboration can open an otherwise blackened-out financial window a crack-letting in enough light to attain corporate goals. Here are some points to consider if you are contemplating this type of deal.

\section{Stand out from the crowd}

Biotechnology is always in the process of reinventing itself. It requires too much time and money to develop innovative drugs to rely on a one-size-fits-all story. This, after all, is why biotechnology executives are so passionate about what they do-there is perhaps no greater challenge in life than running a biotechnology company.

So as continental Europe awakens to the potential of biotechnology, new opportunities to collaborate arise that only those companies willing to step out of the mold can seize. This was recently the case when Ribozyme Pharmaceuticals (RPI, Boulder, CO) created Atugen, a subsidiary in Berlin, Germany. RPI had to step out of the traditional model of how a US biotechnology company operates and refocus its perspective on international opportunities as a way to better leverage their technology. As a result, they strengthened their research capability, gained access to new markets, and improved the focus of each of the two new businesses (see "Forming an international biotechnology spinout: Is it worth it?").

RPI made itself stand out from the crowd as being a candidate for this deal. For

Wolfgang Stoiber is managing director at MPM Capital Advisors LLC, One Cambridge Center, 7th Floor, Cambridge MA 02142 (wstoiber@mpmcapital.com). a biotechnology company looking for financing in tough times, one has to remember that there are more than 2,000 other biotechnology companies worldwide in the same boat. RPI had captured a unique niche with its ribozyme technology based on the Nobel-prize winning research of Tom Cech. Their commitment to developing this technology is reflected in their recent move to use ribozymes as a target discovery and validation tool for genomics.

\section{Cultural considerations play a larger role in international deals as they move closer to implementation.}

In effect, they made themselves stand out not only by their technology, but also by capturing a unique niche in the market. As Jonathan Fleming, general partner of Oxford Bioscience (Boston, MA) puts it, "There is only so much room in a niche, and biotech is all about niches."

So from the perspective of the German government and the private investors in the deal, RPI's capturing of this niche was a good fit with the existing oligonucleotide technologies endemic to German academic science in Berlin. It made good sense to all parties that RPI would create sustainable value by spinning out its target validation business into Atugen. First, it allowed RPI to remain focused on the discovery and development of therapeutics. Second, it allowed the full development of their target validation program as a separate business. Finally, it offered the potential to develop the technology further and to couple it with related areas to further increase its performance.

\section{Overcoming the buzz}

The other side of carving out a distinctive niche for a company is that it can become categorized. It is a sad fact of the biotechnology industry that superficial perceptions about a technology or a company are sometimes perpetuated within a financial or cor- porate market without basis in fact. This "buzz" does not always do justice to the real opportunities in biotechnology companies. For example, one perception that needed to be overcome in this deal was that "Ribozymes never work." Fortunately, presentation of the evidence revealed that the statement was incorrect, and both investors and pharmaceutical executives reacted to the data.

Getting a chance to correct a distorted image of the company or its technology is often the first step in negotiating a deal. Any investor worth his money will do enough due diligence to find the soft spots in any assumption concerning rival technologies, speed of change, or erosion of prices. It is a plus to think ahead and proactively address the issues a partner may have. It is usually not until the air has been cleared about these issues that the true scope of an existing opportunity can be realized. Therefore, it is important for the biotechnology company to anticipate and address as many of these issues as possible up front.

This is especially true with regard to intellectual property. In this deal, the very clear intellectual property rights of RPI drove the value and reduced the perceived risk of developing a partnership. Because each company would have a clear intellectual property position as the result of the deal, the transaction proceeded quickly. For Atugen, being able to fully utilize RPI's highly developed technology would allow it to establish a leadership position in the target-validation race.

\section{Cultural considerations}

In a global industry such as drug development, strategies and business propositions do not show tremendous differences between the US and Europe. However, the closer one gets to implementation, cultural considerations will play a larger role in international deals. In this project there were cultural differences at the level of individuals, organizations, and nations that escalated in complexity as one moved up this chain.

On the individual level, a German accountant with extensive experience in 
East Asia may not have much in common with an American researcher of Mediterranean descent. But what makes their interaction work is the common cause that gives them a strong incentive to understand each other's position.

This incentive needed to be discovered at the organizational level as well. For example, finding the compromise between RPI and the lead investor in Atugen was a challenge of aligning opposed interests. After several rounds of tough negotiations, all the edges were smoothed out and a deal was struck that adequately and fairly reflected the interests of RPI, Atugen, and their investors.

The next level of complexity was reached in negotiating the relationship between Atugen and various government agencies. By the time the deal arrived at this level, everyone had agreed to the goal, but opinions on how to reach it differed substantially. As this transaction was a first in many respects, new ways had to be found and uncharted territory had to be mastered. One difficulty was in overcoming voices that expressed general concern without precise knowledge of the details. It is easy to throw legitimate ventures together with subsidy rip-offs and create a negative feeling about investments from abroad. However, the relevant decision-makers looked at the facts and made their positive decisions accordingly.

At the national level, the way things are done can differ substantially. It begins with banalities such as the way a business lunch is handled, and goes all the way to more serious problems, such as the differences between case law in the US and codified law in Germany. For example, the fact that an employee in Germany has to give three months notice before resigning, as compared to two weeks in the US, illustrates how issues that would never come to the table in a US-only deal can have a significant impact the business planning process.

\section{Implementation}

Win-win is an overused term, but it is still the basis for deals that create sustainable value. Knowing what the other party in a negotiation wants, however, is not always clear. "Communicate, communicate, communicate" is to transactions what "Location, location, location" is to real estate. Because the process of closing a deal is subject to so much uncertainty, there are some practical considerations that should become the "game rules" from the outset.

For one, it always takes more time than anticipated to negotiate deals, so avoiding time constraints during a negotiation strengthens the negotiating position. The documents that accompany the process need to be scrutinized again and again. Any inconsistencies in these documents are likely to delay negotiations substantially, so mistakes need to be eliminated before the documents are handed over. Presentations have an increased chance of success if they are crisp and to the point. Any identifiable weakness has to have an explanation and an action plan as a backup.

Another game rule that can be incredibly important is to narrow down the number of players involved in making the decision. Small, competent teams are a great benefit because they reduce complexity. The same logic applies to reducing the number of potential partners or investors involved in serious discussions fairly early in the process. It helps to avoid spreading resources too thin, and maintains focus on the important prospects.

Finally, once a basic understanding is reached, build and follow a clear schedule to closing. Losing momentum is perhaps the greatest threat to a deal that all parties have agreed to in principle. This lack of momentum will cause all parties to become frustrated, and suddenly the opportunity will begin to seem small when compared to the mountain of difficulties that must be overcome. At such a point it may be beneficial to use person-to-person meetings to break the ice. When facing 10 hours of travel time, jet lag, and a host of missed appointments to negotiate face-to-face over what seems to be an inconsequential point, remember that this trip will probably save a lot of time in the long run. Issues are easier to resolve in face-to-face meetings than in videoconferences or conference calls.

\section{Conclusions}

There is light at the end of the transatlantic tunnel for both parties if they remain focused on the ultimate benefits their companies will receive. Making these deals is really a question of skillful project management: It is as much an issue of being organized and tending to details as it is of motivating all the players to contribute to the common goal.

A team that is able to occasionally laugh under pressure is a key ingredient to balancing the seriousness of the negotiations. More than once, introducing humor into an otherwise deadlocked situation enabled both sides to see that a contentious issue was relatively minor in the context of the big picture. We were fortunate to have such a team at RPI. It greatly contributed to the success of the mission, and we appreciated the opportunity to work with all parties and to get to know the many talented individuals who contributed to the success of the project. 